\title{
IMPLEMENTING CONSTRUCTIVISM APPROACH IN ONLINE WRITING COURSE: LEARNERS' NEED ANALYSIS
}

\author{
Lidwina Sri Ardiasih \\ English Education Study Program, Universitas Terbuka, Indonesia \\ E-mail: lidwina@ecampus.ut.ac.id \\ Emzir \\ Applied Linguistics, Postgraduate of Universitas Negeri Jakarta, Indonesia \\ E-mail: emzir.unj@unj.ac.id \\ Yumna Rasyid \\ Applied Linguistics, Postgraduate of Universitas Negeri Jakarta, Indonesia \\ E-mail: yumna.rasyid@unj.ac.id
}

\begin{abstract}
APA Citation: Ardiasih, L. S., Emzir, \& Rasyid, Y. (2018). Implementing constructivism approach in online writing course. English Review: Journal of English Education, 6(2), 127138. doi: 10.25134/erjee.v6i2.1261.
\end{abstract}

Received: 14-02-2018

Accepted: $23-04-2018$

Published: 01-06-2018

\begin{abstract}
Learning a new language is inevitably working on activities in relation to the four language skills, namely reading, listening, speaking and writing. Reading and listening are categorized as receptive skills, while speaking and writing are productive skills.Differing from the other skills, in developing writing skills learners do not merely focus on the writing products, butmore on its process in which they have to follow certain steps.It is the teacher'sresponsibility toguide the students to develop excellence in writing. Universitas Terbuka (UT), as a higher education institution applying distance learning, has provided an online tutorial (tuton) to enhance students' writing skills. In this study, the writer focuses on students' skills in writing essays, particularly argumentative essays. Furthermore, constructivism is taken as tutor's point of view to evaluate the materials as well as the learning process in the tuton of PBIS4313/Writing III Course. This research aimed at analyzing the students' perceptions about the needs of Writing III Course, regarding both the materials and the learning process, particularly the implementation of the constructivism approach. The descriptive qualitative method was applied in this research. An online survey was carried out to gain some information on the perceptions of the students regarding the learning materials as well as the learning approach needed in this course. From the online survey, it showed that more than 50\% students find difficulties in writing. However, they shared their opinions about the needs of the materials appropriate for Writing III Course as the basic information for further development of the materials. Moreover, this research also resulted in some learning activities to be designed based on the constructivism approach.
\end{abstract}

Keywords: constructivism approach, online tutorial, writing skills, argumentative essay

\section{INTRODUCTION}

Writing is categorized aproductive skill that learners must master in learning a language. In learning a second language or a foreign language, writing skills are considered complex. Learners must be able to put their ideas into the writing products. This requires a lot of practice, which should be done continuously. Brown (2001) explains that for half a century the paradigmin the teaching of writing skills shifted from product-oriented to process-oriented. This is in line with the student-centered learning paradigm in which the teaching of writing skills needs to address the needs of the real learners, including their progress. Therefore, it is expected that learners are accustomed to perform the process of writing with correct procedures and trained in producing and reviewing the results of their writing in order for it to be feasible for the readers. 
The main purpose of practicing writing skills for learners is that they can produce pedadogical writing by focusing on how to generalize their own ideas to the phase of producing the final products (Brown, 2001). Related to this purpose, it is obvious that there is a close relationship between the process approach and the student-centered learning paradigm. Writing involves complex skills such as focusing on spellings, punctuation, word choice/diction, and other aspects of writing. In addition, the learners' writingis the result of their thoughts, concept development, and revision procedures that require the special skills not naturally possessed by learners. Learners cannot obtain these instantly, butmust go through a process.

The principles of the constructivism approach are appropriate to be applied inthe learning of writing skills in line with studentcentered learning principles that are fully focused on learners'needs. By implementing the process-oriented principle, this constructivism approach supports learners in developing their own ideas through the process of writing with the help of teacher's feedback and the revision process to obtain optimal writing results.

Universitas Terbuka (UT) as a distance learning institution offers several courses that train students in writing skills. The PBIS4313/Writing III course is one of the writing skills courses that give students learning experiences in writing various kinds of essays. The online tutorial service or tuton for writing skills is expected to deliver learning materials and activities that are appropriate to the characteristics of UT learners who belong to the adult learning category through their independent as well as autonomous learning process. The discussion of material in this paper focuses on one of the topics in this course i.e. writing argumentative essays. The aim of this paper is analyzing the students' perceptions ofthe needs of the Writing III course, particularly in writing argumentative essays, in terms of both the materials and the implementation of constructivism approach.

\section{METHOD}

This study was a needs analysis that applied a descriptive method with the aims at analyzing the learners' perceptions towards the needs of the Writing III course, particularly in writing argumentative essays, and including both the materials and the learning approach based on the constructivists' point of view. The data collection was conducted through a questionnaire to obtain data and information related to the learners' needs of the materials and the learning methods to be applied in the Writing III course. The questionnaire consists of two forms of questions that are multiple choiceselections and open questions. The questionnaires were distributed during two months from March to May 2017.

The population in this study was UT learners who registered and attended the online learning of the Writing III course provided by UT. The purposive sampling method was used to determine the respondents. The sample selected is the participants of the online tutorial of the Writing III coursefrom the period 2016.2 held from August 29, to October 23, 2016. The data obtained from the questionnaire were analyzed by summarizing in a graph and applying descriptive analysis. All comments or qualitative information obtained from the respondents were coded to determine the category of answers. The use of both quantitative and qualitative methods through questionnaires and observation results of online learning have been processed to support the data triangulation.

\section{RESULTS AND DISCUSSION}

This section discusses the results of the survey describing the learners' perceptions towards the needs of teaching materials and the learning approach to be applied in the tuton of the PBIS4313/Writing III course. The process of the data collection using a questionnaire is presented on the following report. 


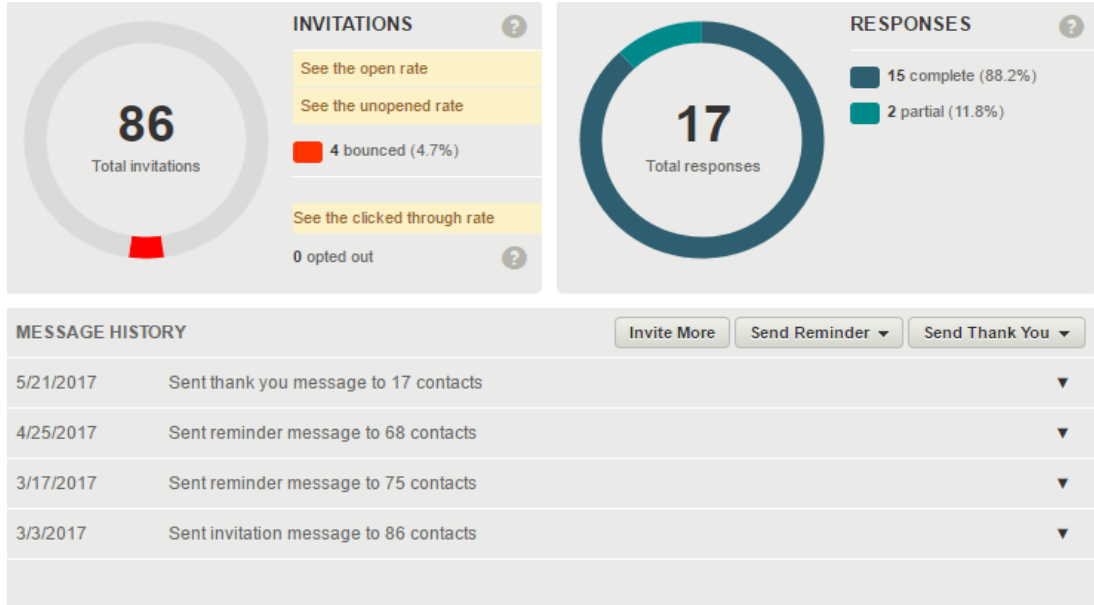

Figure 1. The process report of the online survey

Figure 1 illustrates that during the eight weeks after the questionnaires were sent, the number of respondents who filled out the questionnaire through the online survey was 17 out of 86 respondents, or $20 \%$ of the respondents living throughout the country.

The first part of the questionnaire discusses the respondents' identity which is very important to describe their characteristics. However, in this paper the discussion focuses on the second and the third part as the core parts of the overall information gathering, which discusses the content or teaching materials and the learning process (including the approach to be applied) of the PBIS4313/Writing III Course. Participants were asked to determine the level of the material needs which is divided into four categories, namely "badly needed", "needed", "not needed" and "totally unnecessary".

\section{Learners' perceptions towards the needs of the materials for PBIS4313/Writing III}

The following graph illustrates the analysis of the results of the survey conducted in relation to the needs of learners of the content or subject matter of the tuton of PBIS4313/Writing III course.

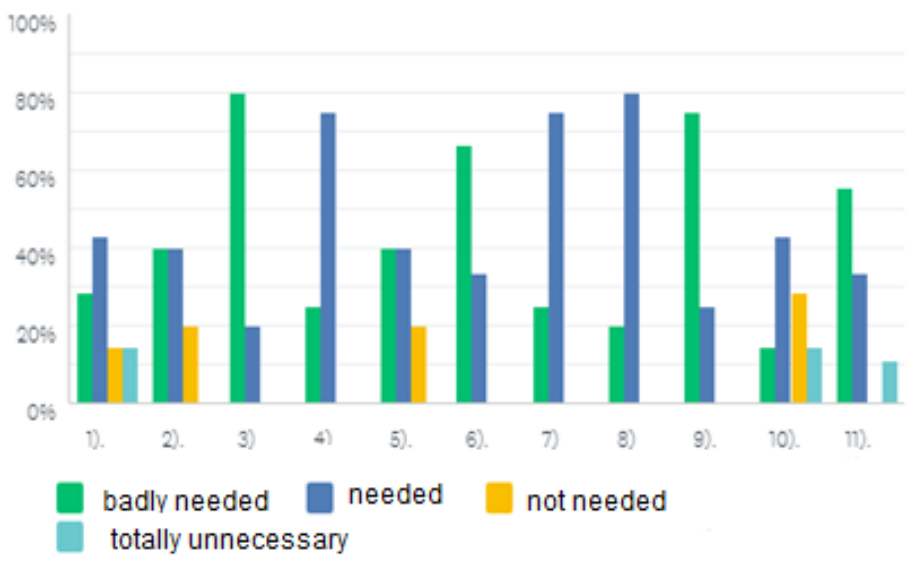

Figure 2. The learners' needs of the contents of PBIS4313/Writing III course

The first material discussed in the questionnaire was about "The Definitions of Argumentative Essay". The results showed that $28.57 \%$ of participants stated this material is badly needed and $42.86 \%$ thought that this material is needed, whereas $14.29 \%$ stated that the material is not badly needed and another
$14.29 \%$ thought it is absolutely not needed. The second material wasabout "The Characteristics of Argumentative Essay". Forty percent of participants stated that the material is badly needed and $40 \%$ said it was needed. However, as much as $20 \%$ of participants thought that this material is not very necessary. 
The next statement relates to the material on how to "Identify Topic Sentences". A total of $25 \%$ of participants stated that the material is badly needed and the remaining $20 \%$ of participants agree with the discussion of this discussion. Furthermore, the fourth statement item was related to "Analyzing the Coherence of the Argumentative Essay" and a total of $25 \%$ of participants stated that the material is badly needed and $75 \%$ said it is needed.

The fifth item was discussing the material about "The Schematic Structure of an Argumentative Essay". There were $40 \%$ of participants who thought that the discussion of the structure of the essay is urgently needed and another $40 \%$ of the participants who supported the opinion by stating that this material is needed. Nevertheless, there were $20 \%$ of participants who stated that the discussion of the material on the Argumentative Essay structure is not necessary. The sixth item raised in this survey is about "Identifying the Components of an Argumentative Essay" (the introductory paragraph, the body paragraph(s), and the concluding paragraph). In this section, as much as $66.67 \%$ stated that the discussion of this material is badly needed and the remaining $33.33 \%$ chose the options needed.

Furthermore, in relation to "The Outline Development of an Argumentative Essay", the survey results were dominated by $75 \%$ of participants who stated that this material is needed, and supported by the remaining $25 \%$ of participants who stated that this material is badly needed. The eighth material is "The Development of Paragraphs of Argumentative Essay with the Correct Schematic Structure", as much as $20 \%$ of participants stated that this material is badly needed, and $80 \%$ said this material is needed.

The "availability of Argumentative Essay examples" is an important statement raised in this survey and the participants' responses were very positive. The results were dominated by $75 \%$ of participants who believed that the availability of these examples is badly needed and another $25 \%$ said this material is needed. Furthermore, the results in relation to the "explanation of the self-assessment components of the Argumentative Essay" remained dominated by as much as $42.86 \%$ of the participants who stated that the explanation of this material is needed. A total of $14.29 \%$ stated that this material is badly needed, while $28.57 \%$ stated they do not really need this material. At the point of this statement, participants who assume that the material explanation of the component of independent assessment is not required at all, number as much as $14.29 \%$.

The last material raised in this survey was the "availability of tips or how to write Argumentative Essay in video programs". This statement received a positive response from $55.56 \%$ of participants who stated that the availability of this video is badly needed, $33.33 \%$ said the video is needed, and as much as $11.11 \%$ thought that the video is not needed at all.

Based on the survey results, it is evident that the survey of content/learning materials for the PBIS4313/Writing III Course, especially the material given in the online tutorial, got very positive responses. The results were dominated by more than $50 \%$ of participants choosing 'badly needed' and 'needed' options against the eleven subject matters discussed. It is indicated that the most needed material is the discussion of "how to identify topic sentences in the argumentative essay", followed by the participants' needs for the Argumentative Essay examples. The next most desired material is that which discusses how to identify the components of the Argumentative Essay (introduction, the body of paragraphs, the concluding paragraph). The development of paragraphs of an

Argumentative Essay with the correct schematic structure is ranked four thin terms of the highest needs of learners in this course. Furthermore, the materials that discuss "how to analyze the coherence of the Argumentative Essay" and the material on "the outline development of the Argumentative Essay" are the next most favored requirement of the participants.

Basically, the results of this survey imply that the eleven subjects or subject matter offered in this survey are needed by participants inthe learning process ofthe online tutorial PBIS4313/Writing III Courses. These 
ENGLISH REVIEW: Journal of English Education Volume 6, Issue 2, June 2018

results are important as underlying factors in the development of online learning models in research in terms of content/material discussion.

\section{Learners' perceptions towards the implementation of constructivism approachin the tuton of the PBIS4313/Writing III}

The next part of the questionnaire discusses the learners' perceptions towards the learning
p-ISSN 2301-7554, e-ISSN 2541-3643

https://journal.uniku.ac.id/index.php/ERJEE

process needed in the tuton of the

PBIS4313/Writing III course. Some

information was collected from the participants in relation to their needs towards the implementation of a constructivism approach (collaborative learning method) in the tuton activities. The following is the results of the participants' information obtained through the implementation of a constructivism approach in the tuton of the PBIS4313/Writing III.

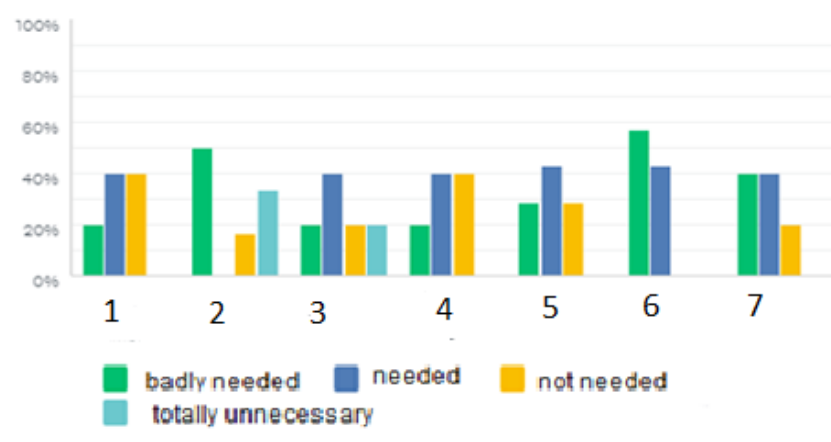

Figure 3. The learners' needs of the implementation of constructivism approach in the tuton of PBIS4313/Writing III

In the previous section, the results were dominated by groups of participants who stated 'badly needed' and 'needed' in most of the statements given. In this section, researchers collect information related to the implementation of a constructivism approach (collaborative learning methods) and the participants' opinions vary widely as shown in Figure 3. There are seven issues raised in this section in relation to what the tutor has to consider. Here are the details.

The first issue raised is the need for tuton participants to interact with each other. A total of $20 \%$ of participants stated that giving participants the opportunity to interact to each other in tuton activities is badly needed and $40 \%$ of participants stated needed. However, $40 \%$ of participants thought that the interactionin the tuton is not necessary. The second statement is related to dividing the participants into several small groups. As much as $50 \%$ of participants responded very positively by declaring that dividing participants into several groups of interaction is badly needed. On the contrary, there were $16.67 \%$ who stated that the dividing participants into interaction groups is not very necessary and even the remaining $33.33 \%$ stated it is not needed at all.

The third statement raises an issue of providing learning activities with a 'dialogue journal' for taking notes of ideas to be exchanged with other members for comments or statements. This writing learning technique is categorized as a method of collaborative learning. In this activity the participants record ideas or ideas in a journal and exchange with other participants for comments or questions. On this issue, participants' responses vary greatly, i.e. $20 \%$ stated that this technique is badly needed, another $40 \%$ said it is needed. In contrast, there were also participants who were less supportive of this technique. As much as $20 \%$ of participants thought that the technique is not very necessary and remaining $20 \%$ stated that this technique is not needed at all.

Statement four raised in this section is the need for "providing instructional activities with Dyadic Essays techniques". This technique consists of an activity in which learners are given a reading text and write 
essay questions and model answers, then they exchange those answers for use as a model. In addition to a dialogue journal, "dyadic essays techniques is another component of collaborative learning methods in which participants write each essay question and answer model, exchange questions, and compare the answers to be used as a model. Participants are quite enthusiastic about this technique. This can be seen from their response to the survey that as many as $20 \%$ said this technique is badly needed and supported by $40 \%$ of participants who declared this technique is needed. However, as much as $40 \%$ thought that this technique is not needed.

In the fifth statement, the researchers raised another technique called peer editing. Peer editing of writing involves critically reviewing and preparing editorial feedback for other participants' essays, reports, arguments, research reports or other writing assignments. In this technique the participants critically review the writings of other participants based on groups that have been made by researchers. In addition to critically reviewing, participants practice preparing editorial feedback for other participants' essays, reports, arguments, research reports or other writing assignments. In this section, the participants' responses were quite good. Based on the percentage of survey results on $28.57 \%$ of participants, it was revealed that the technique is needed, while $28.57 \%$ thought that the technique is not very necessary.

The sixth statement discusses the learners' perceptions towards the needs of another technique called the collaborative writing technique of essay. The learners write essays together for practice and display the writing stages more effectively. The participants' responses regarding this technique is very positive in that $57.14 \%$ stated that this technique is badly needed and the remaining 42.86 stated that this technique is needed.

The last statement discussed by the researcher is a self-assessment for writing to conduct independent evaluations and revise the learners' writing results up to the final results. In this research it was expected that self-assessment guidelines were developed as one of the products. The main purpose of these guidelines is for the participants to conduct independent evaluations and to revise the results of their writing into the final stages by going through the right process. On the issue of providing self-assessment guidelines, the participants showed an excellent response in which as much as $40 \%$ of participants stated that these self-assessment guidelines are badly needed and supported by $40 \%$ of other participants who stated that these are needed. On the contrary, there were $20 \%$ of the participants thought that the self-assessment guidelines are not necessary.

The survey results related to the application of interaction and the constructivism approach, especially the method of collaborative learning, show high enthusiasm of the participants. Figure 3 shows that of the seven issues raised, more than $60 \%$ of participants stated that the application of interaction and the use of collaboratvie writing techniques as the embodiment of the constructivism approach is really needed. The results of this data analysis become the basis for the researcher to consider the collaborative writing techniques in the process of developing the online learning model.

One of the most needed techniques by the participants is the collaborative writing technique in which they can work together and practice writing witheach other through more effective stages. In addition, the participants' enthusiasm towards the use of peer editing techniques in which they can do a critical review of the other participants' writings and give feedback to each other for improving their writing, is quite high.

Utilization of self-assessment guidelines or self-assessment has also taken the highest priority for participants in which as much as $40 \%$ of the participants stated that selfassessment guidelines are urgently needed and the remaining $40 \%$ of the participants stated that these guidelines are needed. Therefore, in the process of developing online learning for argumentative essay writing skills the researcher needs to develop such selfassessment guidelines to assist participants in their writing process. 
ENGLISH REVIEW: Journal of English Education Volume 6, Issue 2, June 2018

\section{Learners' perceptions towards the overall learning process of the tuton of PBIS4313/Writing III}

The open questions are the last parts of the questionnaire which aim at finding out the participants' responses regarding four important things: 1) the frequency of English essay writing, 2) obstacles in writing argumentative essay, 3) obstacles during the tuton PBIS4313/Writing III, and 4) the importance of PBIS4313/Writing III course in
p-ISSN 2301-7554, e-ISSN 2541-3643 https://journal.uniku.ac.id/index.php/ERJEE

supporting the participants' professions. The open questions came with explanatory columns that are open or free of participants. The participants' answers comments, or recommendations are useful to strengthen the options chosenby the participants in the previous parts. The following is the detailed explanation of the results of the open questions. The first open question is whether the participants frequently write essays in English. Here is the result.

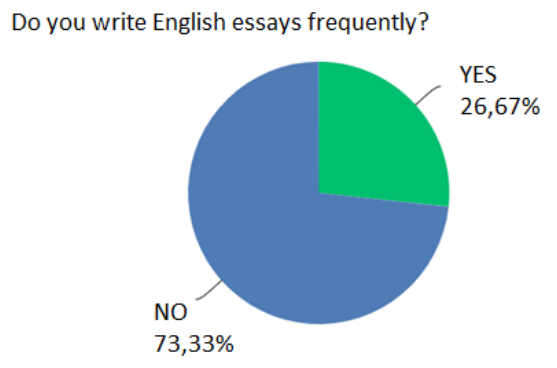

Figure 4. Learners' practice of writing English essays

Regarding the learners' practice of writing essays in English, the survey results show that only $26.67 \%$ were accustomed to writing English essays and as much as $73.33 \%$ stated that they were not used to writing essays in English. The percentage of the participants who were used to writing English essays is very small and there were four participants who put additional explanation of the types of the essays they used to write. The types of essays they normally write are: 1) storytelling, 2) description and narrative (the reason is because it is easy to get), 3) personal experience story, and 4) grammar (additional writing skills).

In terms of the writing process conducted by the participants, the researchers also obtained some information about the constraints faced by participants in their writing process. There are five academic obstacles mentioned by the researcher on the questionnaire and participants have the option to choose more than one obstacle. These constraints are: 1) difficulties in getting ideas to be developed in the writing, 2) lack of information about the characteristics of an argumentative essay, 3) lack of knowledge about appropriate argumentative essay structures, 4) lack of knowledge about appropriate argumentative essay components, and 5) difficulties developing ideas in the form of paragraphs/essays. The results of the survey can be seen in the following figure. 


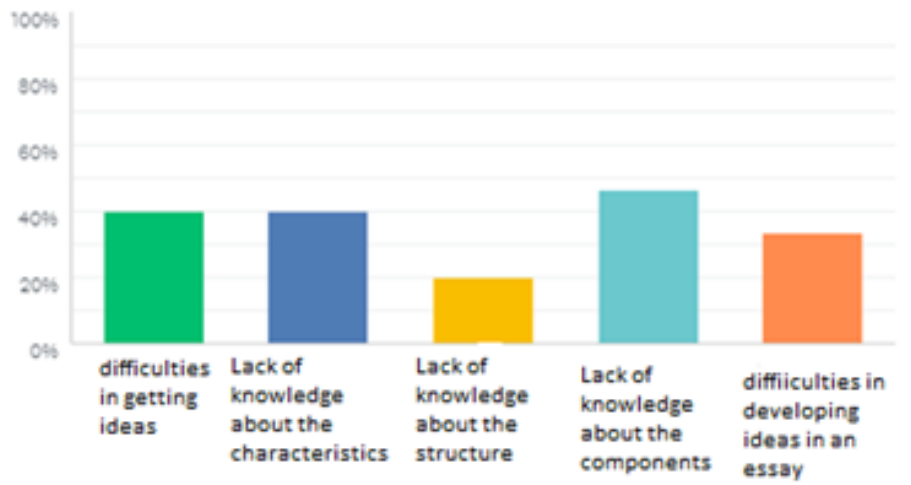

Figure 5. The students' academic obstacles in following the tuton of PBIS4313/Writing III

Figure 5 shows that the biggest obstacle experienced by participants in writing argumentative essays is the lack of knowledge about the appropriate components of an argumentative essay. A total of $46.67 \%$ of the participants claimed that they encountered these constraints and this directly pointed to the needs for individual emphasis on material discussion of the appropriate components of the essay. Moreover, the next two obstacles that the participants experienced most were the lack of knowledge about the characteristics of the argumentative essay and the difficulty of finding ideas.

In this section, there are two participants who commented to clarify the obstacles they experienced especially in relation to the ideas. First, one of the participants stated that "ideas become an important part of essay writing. If the idea is not assembled well it will create difficulties in describing and writing essays" (Respondent 7). Second, another participant reinforced the previous opinion regarding the importance of ideas in the writing process by sharing his experience as follows. "Every time I wrote essays, I always got problems in getting the main ideas as well as developing them. So, sometimes I had to delete and repeat it again because the writing that has been made is not appropriate or even out of the context" (Respondent 5).

The difficulties in getting ideas for this form of writing has been an obstacle that was experienced by $40 \%$ of participants and supported by another $33.33 \%$ who expressed their difficulties in developing their ideas in the form of paragraphs or essays. The results of this survey demonstrate the importance of providing more knowledge to the participants about how to identify ideas and develop them into broader forms.

In relation to the learning process of participants through the tuton of the PBIS4313/Writing III course, some technical obstacles were presented by researchers in the questionnaire to find out about other constraints most experienced by the participants in addition to academic ones. The obstacles offered are: 1) time to follow the tutorial, 2) access of learning resources, 3) cost of the internet subscription, 4) difficulties of writing (e.g. writing assignments), 5) understanding the tutorial material, and 6) limited bandwidth/internet network. Participants may choose more than one option. Here is the description of the survey results obtained by the researcher about the constraints experienced by participants. 


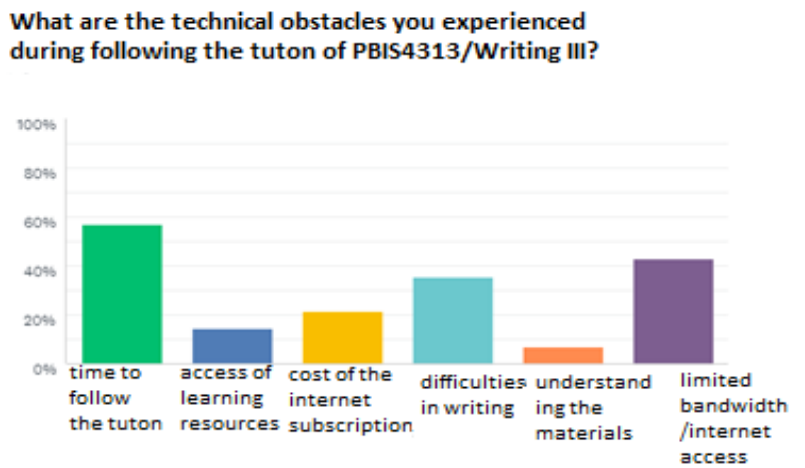

Figure 6. Learners' technical obstacles during following the tuton of PBIS4313/Writing III

Figure 6 describes the technical obstacles experienced by most participants. As much as $57.14 \%$ of the participants experienced time constraints to follow the tutorial. This is very understandable since most of the participants are in-service teachers so they have difficulties arranging time for routine activities at home, workplace, and learning activities in UT. This was confirmed by one of the participants who stated that "due to insufficient time to access the tuton, I was late in following the instructions and even it was untouched" (Respondent 5).

The next most cited technical obstacle is the bandwidth/Internet access, which is experienced by as much as $42.86 \%$ of the participants. This problem has become one of the main obstacles of some participants in following the tuton, especially those living in remote areas and far from Internet access. Furthermore, and no less important, the constraint experienced by as much as $35.71 \%$ of the participants is the difficulty of writing. The participants experienced this at the time of submitting the assignments of writing.
A total of $14.29 \%$ of the participants stated they had problems with learning resources. One of the participants explained that "since I do not have Writing III modules I have difficulties in getting references in accordance with Tuton Writing III, but I often looked for other information related to the material by browsing the Internet" (Respondent 7). This is very relevant to the purpose of the tuton as a means of enriching the material given in printed materials that help participants enrich their knowledge through the online activities available in the tuton. Furthermore, there were participants who mentioned other obstacles related to the technical implementation of the tuton as follows. "I could not submit the assignments because there is no 'submission column' available. I've often experienced this in my account" (Respondent 4).

In this part, the researcher also collected information about the extent to which the PBIS4313/Writing III course has supported the participants' professions. The following figure shows the result of the survey.

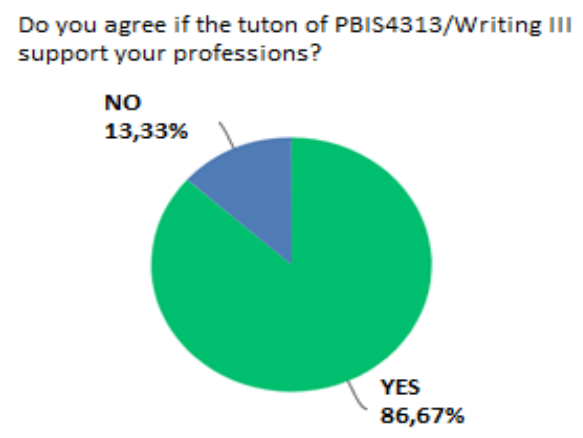

Figure 7. Learners' opinions about the extent to which PBIS4313/Writing III course has supported their professions 
Figure 7 shows the participants' positive response towards this matter in which as much as $86.67 \%$ of the participants stated that this course has supported their professions, whereas the rest $13.33 \%$ stated that this course did not support their professions. Some participants who argued that the PBIS4313/Writing III course supported their professions provided their explanation as follows.

Table 1. Learners' explanation about the extent to which PBIS4313/Writing III course has supported their professions

\begin{tabular}{|c|c|c|}
\hline No & Respondents & Explanations \\
\hline 1. & R 1 & to practice writing and composing in correct English sentences \\
\hline 2. & R 2 & $\begin{array}{l}\text { As an English teacher, I was supported in my teaching ability especially } \\
\text { for text and compose }\end{array}$ \\
\hline 3. & R4 & It helps me understand the kinds of essay and how to develop them \\
\hline 4. & R 6 & $\begin{array}{l}\text { not only support the professions, but in this modern era I learn how to use } \\
\text { such passive and active English communication is common practice }\end{array}$ \\
\hline 5. & R7 & $\begin{array}{l}\text { as an English language teacher in high school, Writing III Course is very } \\
\text { helpful for me in giving examples of good writing in English }\end{array}$ \\
\hline 6. & R 8 & use as a learning material \\
\hline 7. & R 9 & able to improve my competence as a teacher \\
\hline 8. & $\mathrm{R} 10$ & support the teaching and learning activities in schools \\
\hline 9. & R 11 & $\begin{array}{l}\text { this course can help me to have better understanding about the } \\
\text { characteristics and components of writing }\end{array}$ \\
\hline 10. & R 17 & $\begin{array}{l}\text { for the development of the profession of teachers, then make the essay a } \\
\text { means to develop the talent of writing and developing ideas. }\end{array}$ \\
\hline
\end{tabular}

In a service, the users' satisfaction becomes the main goal to be achieved. In this study the researcher also looked at the participants' satisfaction with the tuton of PBIS4313/Writing III course as a whole. Here is an overview of the survey results.

Are you satisfied with the tuton of PBIS4313/Writing III?

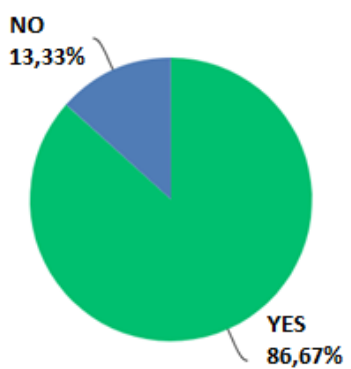

Figure 8. Learners' opinions about their satisfaction with the tuton of PBIS4313/Writing III course

The survey results showed that most participants were satisfied with the tuton service in this course that is as much as $86.67 \%$ and only $13.33 \%$ who expressed dissatisfaction with the tuton service they have followed. In this section, the researcher gives a recommendation, suggestion, and feedback column about the participants' reasons of being satisfied with the tuton of PBIS4313/Writing III course as described in the following table.

Table 2. Learners' comments and recommendations in relation to PBIS4313/Writing III course

\begin{tabular}{cccc}
\hline No & Respondents & & Explanations \\
\hline 1. & R 1 & It's pretty good & \\
\hline
\end{tabular}




\begin{tabular}{|c|c|c|}
\hline 2. & R 2 & $\begin{array}{l}\text { Yes, Because there is a guide in the form of material and material } \\
\text { analysis }\end{array}$ \\
\hline 3. & R 6 & $\begin{array}{l}\text { Because I can find out how the arrangement of the writing and } \\
\text { pronunciation of English which is good and correct }\end{array}$ \\
\hline 4. & R 7 & $\begin{array}{l}\text { I am very satisfied with the material given in Tuton Writing III } \\
\text { especially on the material in the form of video because the material } \\
\text { can be delivered properly }\end{array}$ \\
\hline 5. & R 8 & should be presented more communicatively \\
\hline 6. & R 10 & more lectures should be given \\
\hline 7. & R 11 & sometimes I do not understand the material presented \\
\hline 8. & R 17 & $\begin{array}{l}\text { materials composed starting from Writing I should be sustained and } \\
\text { starting at a simple stage since vocabulary constraints are a classic } \\
\text { problem for beginners }\end{array}$ \\
\hline
\end{tabular}

Based on the results of the survey, there are some important things related to the presentation of teaching materials and online tutorials in the tuton of PBIS4313/Writing III. Re-examining the theoretical studies discussed earlier that the process of selecting instructional materials should be tailored to the needs of the learners as well as the learning objectives, has resulted in several criteria that the instructor has fulfilled.

One of the important items that has been implemented is the selection of topics on the tuton that match the material discussed so that learners can gain a meaningful learning experience. The responses of the participants are good and they are active in responding and interacting with both the tutor and the learners themselves. In the beginning, learners had difficulties in understanding the teaching materials they obtained, but they were greatly helped by the tuton support services. It is shown by their satisfaction statement in which over $60 \%$ of the respondents stated that they were very satisfied and felt very supported in understanding the teaching materials with the tuton service. In addition to the selection of topics, the types of essays raised in the tuton also has described the ability of tutors in determining the material in accordance with the needs of learners. However, there are several forms of essays that need to be replaced for learners' learning outcomes to be more meaningful.

Reviewing the survey results from the constructivism approach points of view, the participants have implied their experiences of practicing this approach though it was not optimum. This can be determined from their opinions about their interests in being able to express their opinions, ideas, knowledge, and even share experiences with tutors and other participants. Through the discussion forum or other online facilities, there is an opportunity for learners to collaborate with other participants if needed. Thus, the learners have an opportunity to build their own knowledge. Furthermore, the discussion on the assigned tasks have represented a constructivism approach in which tutors are not limited to asking questions to answer, but rather on assigning tasks to learners to produce their own writing through the construction of their ideas or knowledge. The disadvantage found in this process is the lack of opportunity for participants to receive feedbacks from the tutor for the improvement of his/her writing.

\section{CONCLUSION}

It is important for educators to evaluate some aspects of the teaching and learning, including the materials, the strategies, as well as the assessments, by conducting a learner need analysis. This paper has delivered the result of a study in order to obtain some information about the learners' perceptions about the materials related to writing argumentative essays and the implementation of a constructivism approach in an online writing course. From the overall discussion, it is concluded that some topics be taken as the highest priorities to discuss in a writing course for advanced level learners, i.e. how to identify some main ideas as well as how to develop them into a good argumentative essay by considering some appropriate writing aspects in its process. Moreover, there is a possibility to offer a collaborative writing technique in an online writing course. This 
technique is the embodiment of the constructivism approach in which the learners can build their own knowledge about the subject based on the prior knowledge, learning experiences, as well as the new knowledge they get from the learning process. Therefore, it is another challenge for a language instructor to create an online course by applying a constructivism approach, particularly the online collaborative writing technique, in order to enhance the learners' writing skills.

\section{REFERENCES}

Badger, R., \& White, G. (2000). A process genre approach to teaching writing. English Language Teaching Journal, 54(2), 153-160. DOI: 0.1093/elt/54.2.153.

Barkley, E. F., Cross, K. P., \& Major, C. H. (2005). Collaborative learning techniques. San Fransisco: Jossey-Bass.

Brown, H. D. (2001). Teaching by principles: An interactive approach to language pedagogy. New York: Pearson Education Inc.

Knapp, P., \& Watkins, M. (2005). Genre, text, grammar: Technologies for teaching and assessing writing. Sidney: University of New South Wales.

Mason, R., \& Rennie, F. (2006). E-learning: The key concepts. New York: Routledge.

Oshima, A., \& Hogue, A. (1999). Writing academic English ( $3^{\text {rd }} e d$.). USA: Addison-Wesley Publishing Company.

Renkema, J. (1993). Discourse studies: An introductory textbook. Amsterdam: John Benjamins Publishing Co.

Richardson, V. (1997). Constructivist teacher education: Building a world of new understandings. London: Falmer Press.

Simonson, M., Smaldino, S., \& Svacek, S. M. (2012). Teaching and learning at a distance: Foundations of distance education. Boston: Pearson Education Inc.

Wang, P. (2011). Constructivism and learner autonomy in foreign language teaching and learning: To what extent does theory inform practice. Theory and Practice in Language Studies, 1(3), 273-277. DOI: $10.4304 /$ tpls.1.3.273-277 .

Zuhairi, A., Adnan, I., \& Thaib, D. (2007). Provision of student learning support services in a large-scale distance education system at Universitas Terbuka, Indonesia. Turkish Online Journal of Distance Education-TOJDE, 8(4), 44-64. 